Ann. Sci. For., 1984, 41 (2), 249-250

Résumé de thèse

\title{
Contribution à l'étude du couple Fomes annosus-épicéa : variabilité de l'hôte et de l'agent pathogène : (Contribution to the study of Fomes annosus on Norway spruce : host and pathogen variability)
}

\author{
Marie-Hélène Thibault * \\ I.N.R.A., Laboratoire de Pathologie forestière \\ Centre de Recherches forestieres de Nancy \\ Champenoux, F 54280 Seichamps
}

L'étude a porté sur une collection de 46 isolats de fomes annosus, constituée à partir d'épicéas (Picea abics (L.) Karst.) infectés naturellement; ces isolats ont élé définis initialement par leur vitesse de propagation dans les arbres où ils ont été isolés. Les caractéristiques suivantes des isolats ont été déterminées : croissance linéaire et pondérale sur divers milicux de culture, activité laccase extracellulaire, croissance in vitro sur sciure frâiche d'épicéa ( "lest sciure»), sensibilité aux vapcurs de terpènes ( $\alpha$ et $\beta$-pinène, limonène), et croissance mycélienne dans les troncs d'épicéa, obtenue après inoculation. Le pouvoir lignivore global et l'activité cellulolytique d'une partie de ces isolats étaient connus par ailleurs.

Chaque caractère étudié a révélé une grande variabilité du comportement des isolats, particulièrement en ce qui concerne la sécrétion de laccase, et la sensibilité aux terpènes.

Les coefficients de corrélation linéaire entre ces diverses mesures prises deux à deux ont été calculés : les caractères étudiés sont le plus souvent indépendants ; en particulier le caractère initial (croissance dans l'arbre) est indépendant de tous les caractères mesurés in vitro ou par inoculation. Un groupe de corrélations négatives a été obtenu entre croissance pondérale d'une part, et pouvoir lignivore, activité cellulolytique, résultats des inoculations ou croissance sur sciure d'épicéa d'autre part : ces corrélations vont dans le même sens que des observations antérieures révélant l'existence d'une corrélation négative entre la croissance in vitro et la croissance

* Thèse de docteur de $3^{\text {e }}$ cycle; Université Pierre et Marie Curie, Paris VI, 7 décembre 1982. 
des isolats dans larbre. Il existe enlin une corrélation négative entre la sensibilité des isolats au pinène, el le pourcentage de réussite des inoculations. La signification de ces corrélations est discutée.

Par ailleurs. le « lest sciure " a été appliqué a la comparaison des croissances de deux isolats sur 100 sciures de bois d'épicéas appartenant à différentes provenances européennes : par ce lest, la variabilité de l'épicéa est apparue grande at sein d'une provenance, alors que les résultats obtenus entre provenances ne sont pas significativement différents. Ces résultats sont en aceord avec les données classiques concernant la variabilité de l'épicéa, obtenues notamment par la méthode des inoculations.

Enfin, une technique de confrontation in vitro de plantules d'épicéa et de cultures de fomes annosus a permis dobserver sur les plantules des symptomes constants, et de définir un système de notation des symptômes reflétant des différences de comportement liées à lisolat choisi ou à lâge des plantules.

L'intérêt que représentent ces diverses techniques d'étude de l'hôte ( Test sciure", confrontations plantules- $F$. annosus, ou technique classique d'inoculation) est également discuté. 